\title{
The Relationships of Texture and Hydrophysical Properties in Soil Profiles Under Selected Exotic Trees in the Context of Climate Change in Central Europe
}

\author{
Nora Polláková1", Vladimír Šimanský1, Jerzy Jonczak² \\ 1 Department of Soil Science, Faculty of Agrobiology and Food Resources, Slovak University of Agriculture, \\ Tr. A. Hlinku 2, 94976 Nitra, Slovakia \\ 2 Department of Soil Environment Sciences, Warsaw University of Life Sciences, Nowoursynowska St. 159, \\ 02-776 Warsaw, Poland \\ * Corresponding author's e-mail: nora.pollakova@uniag.sk
}

\begin{abstract}
Suitable soil and environmental conditions are the main prerequisites for successful growth of plants. Generally, all soil properties are substantially affected by textural composition. Therefore, the objective of the study was to test the interrelationships between particle size distribution and such physical soil properties, which usually predetermine the survival/death of plants, since they significantly affect the content and availability of water and air. Textural composition and physical soil properties were studied in profiles under monocultures of selected exotic trees in Arboretum Mlyn̆any, Slovakia. The results showed that medium-textured dominated in topsoils, whereas heavy-textured classes were dominant in luvic and stagnic horizons. Evaluation of entire profiles had confirmed standard, expected relationships between the individual grain fractions and soil physical properties. However, differences have occurred when the correlations between texture and physical properties in individual horizons were evaluated. Considering entire soil profiles, increased sand content significantly supported drainage of rainwater and soil aeration; silt contributed to increase the total porosity and aeration as well as available water capacity; clay contributed to the decrease in the available water capacity, total, and particularly coarse porosity and aeration, and to rise water retention, as well as the values of the wilting point. The results showed silt as key fraction providing suitable hydrophysical properties for the survival and growth of trees introduced in Arboretum. In compacted luvic and stagnic horizons, silt was significantly involved in the formation of total, and particularly coarse porosity and thereby increase soil aeration, while conversely, in loose topsoils just silt fraction significantly contributed to the reduction of coarse pores and increase of fine capillary pores and therefore water retention. In loose eluvial horizons, the silt contributed to significant increases in capillary porosity and water availability, which is essential in terms of meeting the plant needs.
\end{abstract}

Keywords: available water; drought; porosity; soil aeration; soil texture; wilting point

\section{INTRODUCTION}

Soil and climatic conditions are key attributes for the survival and adaptation of non-native plant species in the environment. Moreover, regarding the tree, i.e. long-lived plants, these are greatly influenced by the ongoing climate change during their growing in the place where they were introduced. Significant climate changes in Slovakia occurred especially in the period of 1989-2017, when local or nationwide drought was much more frequent, caused mainly by long periods of relatively warm weather with little rainfall [Ministry of Environment 2017]. This was accompanied by a higher potential evapotranspiration (increases with the rising air temperature and saturation deficit) and actual evapotranspiration (beside temperature considers also precipitation and the soil water availability) in the period of 1991-2016 compared to the period of 1951-1990 [Gera et al. 2019]. According to European Environment Agency [2017], that average annual temperature in Europe increased by $1.45-1.59^{\circ} \mathrm{C}$ in 2006-2015 as compared to the pre-industrial 
period. Moreover, the meteorological and hydrological droughts frequency highly increased over all Europe, mainly in south-western and central parts (Mediterranean and Carpathian regions). This trend is projected to continue.

Sufficient volume and availability of water to plants is an important soil-climatic factor, which significantly determines the vitality and survival of plants, especially when grown in no-native environment. The amount of soil water available to plants varies depending on characteristics of soil (mainly texture) as well as plant, especially the roots distribution and rooting depth [Hosseini et al. 2016]. Textural composition fundamentally affects the hydrophysical properties of soil such as moisture and aeration, porosity, water and air capacity. Much water retention in soils is associated with clay fraction [Kutílek 1978, Safadoust et al. 2014]. Therefore, soil physical properties, mainly those which provide plants with adequate water and aeration, must be evaluated in context with texture.

Already in the past, farmers knew that the soil containing high amount of sand is easily cultivable; however, it weakly retains water and dries quickly. Conversely, when soil contains high amount of fine clay particles, the cultivation will be difficult, but soil retains more water and nutrients. Thus, people tried to recognize the relationships between soil texture and physical properties for centuries, but they still remain complex. Nowadays, the research of mentioned relationships is at a high level and their evaluation is more sophisticated. For example, it may be carried out by means of surface fractal dimension [Ghanbrian-Alavijeh and Millán 2009], or through special models [Marković et al. 2015, De Paepe et al. 2017], or as related to the $\mathrm{CaCO}_{3}$ concentration [Safadoust et al. 2014], or the soil organic matter content [Wall and Heiskanen 2009, Hosseini et al. 2016].

Soil textural composition is an essential factor deciding on the ways of land uses or possibilities of growing various plants. Favourable soil physical and textural properties may help in adaption to new soil-environment conditions, also to the exotic trees. Therefore, the objective of the study was to test the interrelationships between particle size distribution and such physical soil properties, which usually decide on the survival or death of plants, since they significantly affect the content and availability of water and air.

\section{MATERIAL AND METHODS}

\section{Locality description}

In Arboretum Mlyňany $\left(48^{\circ} 19^{\prime} \mathrm{N}\right.$ and $18^{\circ} 21^{\prime} \mathrm{E}$ ), the introduction, i.e. intentional plantation of non-native tree species, has been carried out since year 1892, with the aim to prove exotic trees viability in the soil-climatic conditions of Slovakia. Arboretum Mlyňany is located in southern Slovakia, in the river Žitava valley, on undulated terrain close to Hronský Inovec and Tribeč mountains (Fig. 1).

The altitude of Arboretum is $165-217 \mathrm{~m}$ asl and acreage is 67 ha. Geobotanically, the locality belongs to the Pannonian area, to the south region of xerotherm area of West Carpathian. Guercetocarpinteum forest was indigenous in this area. The parent material on this area is represented by Neogene clays, sands and rubble sands, which are covered by wind-deposited loess, mostly decarbonated [Cifra 1958]. The locality is characterized by warm and dry continental climate, with mean annual temperature of $10.6^{\circ} \mathrm{C}$ and total precipitation of $578 \mathrm{~mm}$ [Hot'ka and Barta 2012]. Ferus et al. [2020] stated that meteorological observations regularly performed in Arboretum showed the past thirty years as being under the influence of global warming, accompanied by increased temperature and decreased precipitation.

\section{Soil sampling and analyses}

For this experiment, seven sampling sites were chosen with the intention to include all soils classified at area of Arboretum [Polláková 2018]. The physical and textural properties were studied in seven soil profiles. Profiles: 1 Cutanic Luvisol Anthric under dense monoculture of Chamaecyparis lawsoniana (A. Murray, Parl), 2 Luvic Chernozem Anthric under Thuja orientalis (L.), 3 Stagnic Cutanic Luvisol Anthric under Juniperus Chinensis (L.), 4 Stagnic Cutanic Luvisol under Picea orientalis (L.), 5 Albic Stagnic Luvisol under Liriodendron tulipifera (L.), profiles 6 and 7 Fragic Stagnic Retisol under Thuja plicata (Donn ex D. Don) and Pinus nigra (Arnold).

Undisturbed soil samples $\left(100 \mathrm{~cm}^{3}\right)$ were collected in three repetitions using steel cylinders per each of $0.1 \mathrm{~m}$ layer to the depth of 0.8 or $0.9 \mathrm{~m}$. In laboratory, the physical properties were determined using standard analytical methods [Kobza 


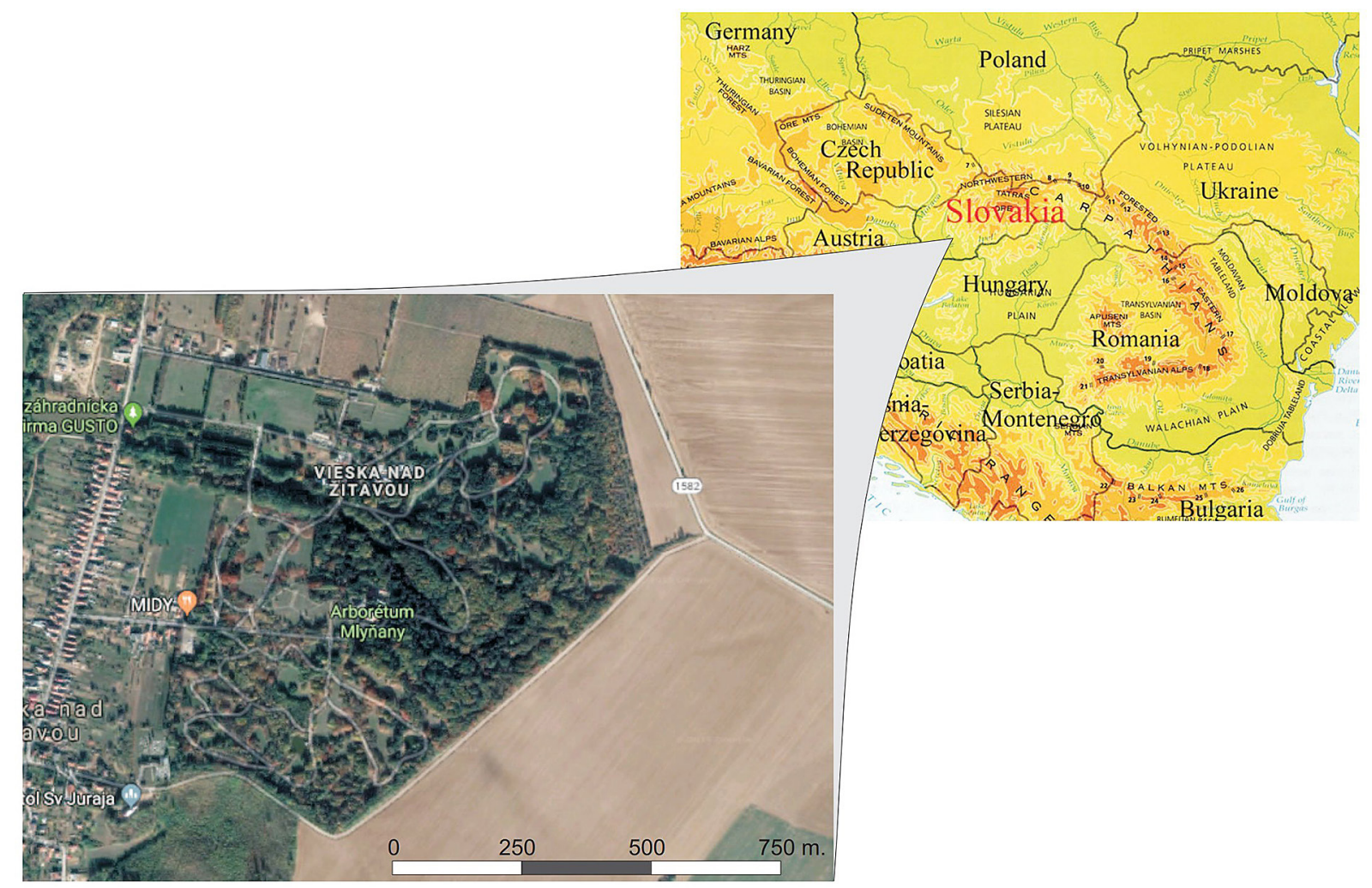

Figure 1. The location of Arboretum Mlyňany, Slovakia

et al. 2011]. The results of physical data are detailed in Polláková et al. [2017].

The textural composition was determined for each horizon using the pipette and sieve method [Kobza et al. 2011]. Each sample was divided into five particle-size fractions, where: $\mathrm{CaCO}_{3}$ was dissolved by $2 \mathrm{~mol} \mathrm{dm}^{-3} \mathrm{HCl}$, organic matter was decomposed by $6 \% \mathrm{H}_{2} \mathrm{O}_{2}$. After repeated washing, the samples were dispersed using the solution of $0.06 \mathrm{~mol} \mathrm{dm}^{-3}\left(\mathrm{NaPO}_{3}\right)_{6}$ and $0.075 \mathrm{~mol}$ $\mathrm{dm}^{-3} \mathrm{Na}_{2} \mathrm{CO}_{3}$. In this study, the amount of sand $(2-0.05 \mathrm{~mm})$ represents the sum of coarse sand $(2-0.25 \mathrm{~mm})$ with medium and fine sand $(0.25-$ $0.05 \mathrm{~mm})$. The amount of silt $(0.05-0.002 \mathrm{~mm})$ is represented as the sum of coarse silt $(0.05-$ $0.01 \mathrm{~mm})$ with medium and fine silt $(0.01-$ $0.002 \mathrm{~mm}$ ), the amount of particles $<0.01 \mathrm{~mm}$ as the sum of medium and fine silt $(0.01-0.002 \mathrm{~mm})$ and clay $(<0.002 \mathrm{~mm})$.

All analyses were performed in three replications and detailed results were reported in Polláková et al. [2017]. In order to determine the significance of correlations, the Pearson correlation was used. The links between the particle-size distribution and physical parameters were determined by a correlation matrix using Statistica software package [2008].

\section{RESULTS AND DISCUSSIONS}

\section{Basic climatic data influencing the adaptation of introduced trees in the Arboretum Mlyñany}

The soil-climatic conditions considerably determine the survival and adaptation of the introduced tree species in the new environment, especially when the trees have been imported from other continents, with distinct soil and climate conditions. In the Arboretum Mlyňany, the Meteorological observatory was established and regular recording of climatic data began in 1971. Until that time, the Arboretum used the data measured in Tesáre n. Žitavou (2.5 km away from Arboretum). The recorded data are presented in Table 1 and in Figure 2. From the results it follows that compared to long-term average data (1901-1950) presented in Cifra [1958], the mean annual air temperature increased by $1.6^{\circ} \mathrm{C}(17.8 \%)$ and precipitation decreased by $8.5 \%$ (long-term averages in years 1971-2011) [Hot'ka and Barta, 2012]. The average annual temperature increased over the period $1971-2011$ by $0.031^{\circ} \mathrm{C}$ per year, which represents a significant increase by $1.24{ }^{\circ} \mathrm{C}$ in 40 years (Figure 2 ), while the decrease of average annual precipitation over the mentioned period was not significant. 
Table 1. Long-term averages of precipitation and temperature in Tesáre n. Žitavou (1901-1950) and Arboretum Mlyňany (1971-2011)

\begin{tabular}{|l|c|c|}
\hline \multirow{2}{*}{ years } & $1901-1950$ & 1971-2011 \\
\cline { 2 - 3 } & \multicolumn{2}{|c|}{ long-term average } \\
\hline Precipitation $(\mathrm{mm})$ & 632 & 578 \\
\hline Temperature $\left({ }^{\circ} \mathrm{C}\right)$ & 9.0 & 10.6 \\
\hline & {$[$ Cifra 1958] } & [Hot'ka and Barta 2012] \\
\hline
\end{tabular}

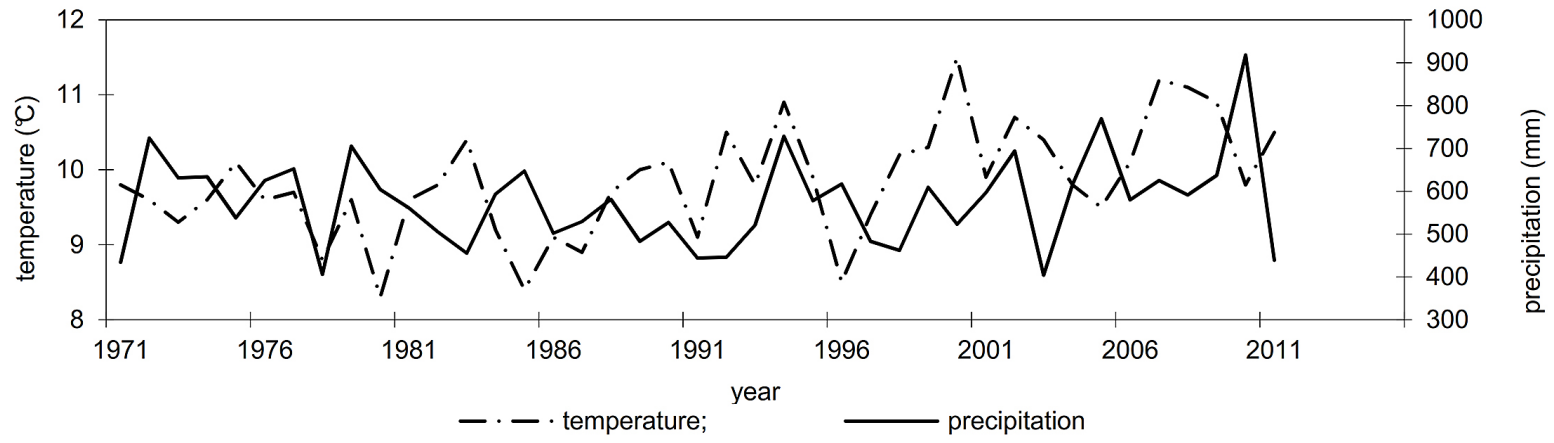

Figure 2. Mean annual temperature and mean annual total precipitation in Arboretum Mlyňany in years 1971-2011[Hrubík and Hot’ka 2007, Hrubík and Holečková 2016]

The above-mentioned data clearly indicate a considerable rising trend in temperature and a slight decrease in precipitation, which, unfortunately, is accumulated mainly in sporadic episodes of several days with high rainfall, while the temperature and long-term periods of drought increase. Ištoňa and Pavlenda [2011] stated that mainly in summer, long periods of drought often occur in the area, during which the soil moisture drops to the semi-arid intervals. Čimo et al. [2020] confirmed the increased mean annual air temperatures in the period of 1961-2010, and also stated that the greatest increase was recorded in the period of 1981-2010.

Confirming data were also reported in the study of Mezősi et al. [2016] from which it is evident that the climate models project an increasing drought hazard for the Carpathian Basin in Central Europe, the south region of Slovakia as well as Arboretum Mlyňany are also situated. The authors stated that based on the results of Palfai Drought Index, nowadays, moderate droughts are characterised for the drought years, but in the future, the moderate droughts may be replaced by more severe ones.

From the trends reported it follows that in the near future a further increase in temperature and decrease in rainfall can be expected, which may adversely affect the survival of introduced trees. It is therefore necessary to determine the linking of climate, soil and living organisms for which the soil is a natural habitat. Recent results of our research have shown that the investigated introduced trees have adapted to the soil-environment conditions in the Arboretum Mlyňany, including those exotic trees that according to Huxley et al. [1992] require high soil humidity and sufficient content of available water (Chamaecyparis lawsoniana, Liriodendron tulipifera, Thuja plicata). Among others, the reason could be a suitable combination of soil textural and physical properties, the detailed characteristics of which were reported in Polláková et al. [2017].

\section{Particle-size distribution in studied soil profiles}

Soil textural class is a permanent and natural soil characteristic, which significantly influences the availability of water and aeration. Mediumtextured classes are dominant in topsoils, whereas heavy-textured classes prevail in luvic (lv) and stagnic (st) horizons. The most represented textural classes were loam, silty loam, sandy loam, clay loam and clay (Figure 3 ).

In all profiles, the $1 \mathrm{v}$ and especially st horizons were greatly enriched by clay, which indicated its considerable migration from the upper to the subsurface horizons in the process of lessivage. Textural differentiation in all profiles was 

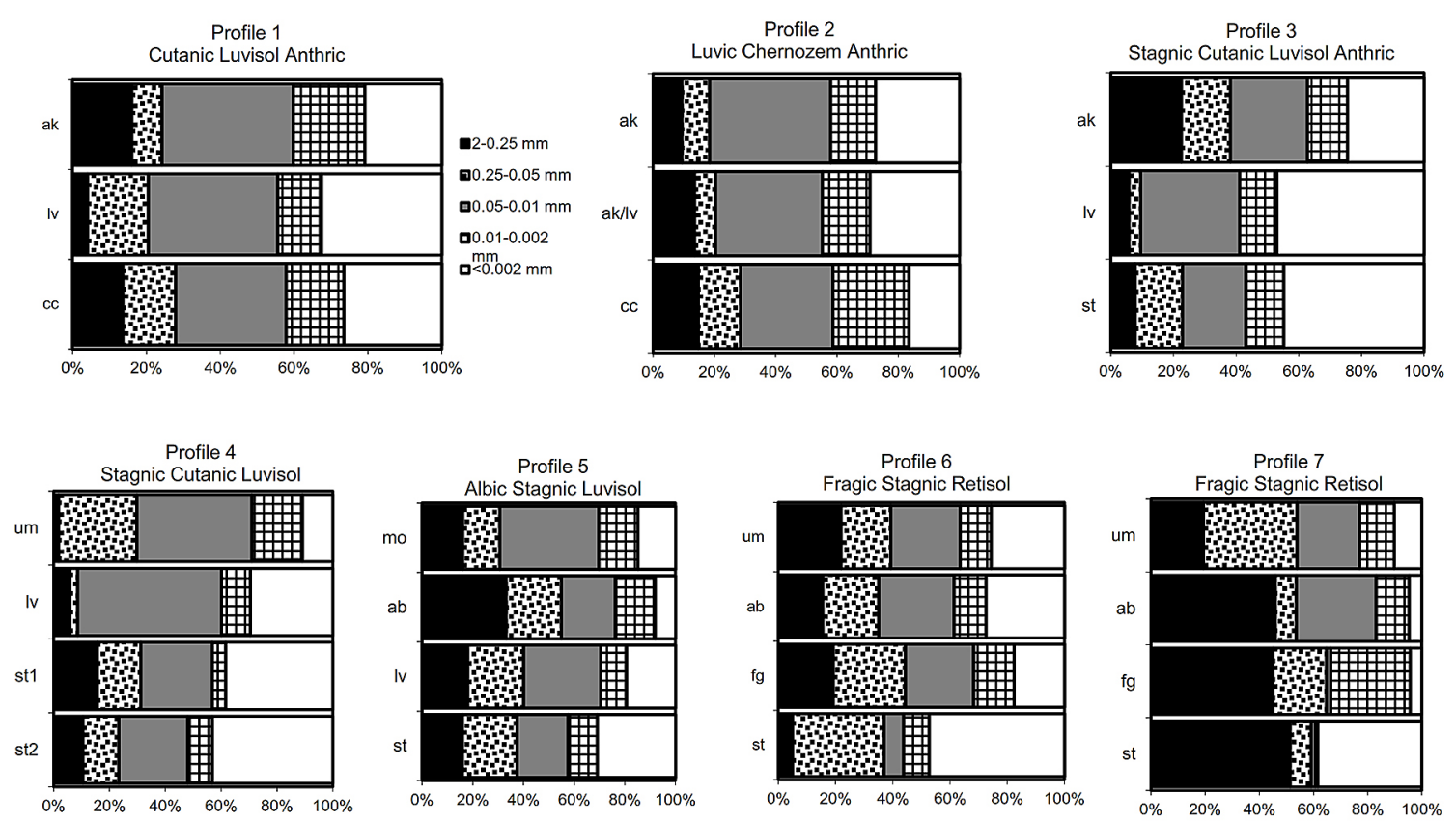

Figure 3. Particle size distribution in profiles, ak - anthric, ak/lv - intermediary, um umbric, mo - molic, ab - albic, lv - luvic, fg - fragic, st - stagnic, cc - calcic

higher than 1.57, and the most considerable was found in the profile 7 (Fragic Stagnic Retisol) between fragic ( $\mathrm{fg}$ ) and st horizons 8.88 , in profile 6 (Fragic Stagnic Retisol 2.70) and profile 5 (Albic Stagnic Luvisol 2.42). Such a significant lessivage in these profiles was supported by high percentage of sand.

Beside Luvic Chernozem Anthric, all examined profiles contained compacted, clay-enriched lv and especially st horizons (Figure 3). Generally, the horizons containing high percentage of clay suffer from poor aeration and soil is weakly permeable or impermeable for water [Heiskanen et al. 2016]. On the other hand, higher content of sand in soil (profiles 5-7) allows easier water utilization by plants; however, it also accelerates the drainage and decrease the content of plant available water [Zangiabadi et al. 2017]. Therefore, during long periods of drought, which is evident in southern Slovakia particularly during last twenty years [Ištoňa and Pavlenda 2011], trees can suffer from water deficiency. Hypoxia, water stress, and mechanical impedance to root growth all change when the water content of the soil is altered [Whitmore and Whalley 2009].

\section{Relationships between the textural and physical parameters in entire soil profiles}

The correlations between particle size distribution and physical parameters studied in entire soil profiles are included in Table 2. The obtained results confirmed standard, expected relationships between the individual grain fractions and soil physical properties. Sand fraction was in highly significant positive correlation with coarse porosity $\left(\mathrm{P}_{\mathrm{N}}\right)$ and consequently with air filled porosity $\left(\mathrm{V}_{\mathrm{A}}\right)$; however, it was in highly negative correlation with fine i.e. capillary pores $\left(\mathrm{P}_{\mathrm{C}}\right)$ and so water retention and maximum capillary water capacity $\left(\theta_{\text {CMC }}\right)$. This confirmed the general rule that increased sand content in a profile favours quick water drainage. Plants can easily utilize the water from sand particles, since they retain water weakly [Poesen and Lavee 1994, Fulajtár 2006]. Minasny and McBratney [2003] also proved that more energy is required by a plant to absorb unit mass of plant available water from a fine textured soil than from a coarse-textured soil. In accordance, Lal [1979] indicated the negative effects of sand on wilting point. Moreover, in the presented study, the wilting point $\left(\theta_{\mathrm{v}}\right)$ was in highly negative correlation with the amount of sand.

The silt significantly contributed to a reduction in soil bulk density $\left(\rho_{\mathrm{d}}\right)$ and $\theta_{\mathrm{V}}$ as well as significantly increased total porosity $\left(\mathrm{P}_{\mathrm{T}}\right)$, available water capacity $\left(\theta_{\mathrm{P}}\right), \theta_{\mathrm{CMC}}$ and $\mathrm{V}_{\mathrm{A}}$.

Clay highly negatively contributed to a decrease of $\mathrm{P}_{\mathrm{T}}$, and in agreement with literature [Fulajtár 2006, Heiskanen et al. 2016] mainly $\mathrm{P}_{\mathrm{N}}$; hence, decreased aeration in soil and $\theta_{\mathrm{P}}$. In the studied profiles, clay significantly 
Table 2. Pearson correlation coefficients (r) between particle-size distribution and physical parameters in entire soil profiles

\begin{tabular}{|c|c|c|c|c|c|c|c|c|}
\hline Particle size & $\rho_{d}$ & $P_{T}$ & $P_{N}$ & $P_{C}$ & $\Theta_{\mathrm{CMC}}$ & $\Theta \mathrm{v}$ & $\Theta p$ & $V_{A}$ \\
\hline $\mathrm{mm}$ & $\mathrm{t} \mathrm{m}^{-3}$ & \multicolumn{7}{|c|}{$\%$} \\
\hline $2-0.05$ & $-0.014^{\text {n.s. }}$ & $0.039^{\text {n.s. }}$ & $0.332^{* * *}$ & $-0.533^{* * *}$ & $-0.491^{* * *}$ & $-0.574^{\star * *}$ & $-0.027^{\text {n.s. }}$ & $0.336^{* * *}$ \\
\hline $0.05-0.002$ & $-0.377^{\star * *}$ & $0.398^{\star \star \star}$ & $0.156^{\text {n.s. }}$ & $0.123^{\text {n.s. }}$ & $0.219^{\star *}$ & $-0.185^{\star}$ & $0.362^{* * *}$ & $0.175^{*}$ \\
\hline$<0.002$ & $0.380^{* * *}$ & $-0.430^{* * *}$ & $-0.538^{* * *}$ & $0.506^{* * *}$ & $0.363^{* * *}$ & $0.850^{* * *}$ & $-0.318^{* * *}$ & $-0.562^{* \star \star}$ \\
\hline$<0.01$ & $0.410^{\star * *}$ & $-0.442^{\star * *}$ & $-0.532^{* * *}$ & $0.465^{\star * *}$ & $0.332^{* * *}$ & $0.812^{\star * *}$ & $-0.326^{\star * *}$ & $-0.553^{\star * *}$ \\
\hline
\end{tabular}

(*) $\mathrm{P}<0.05 ;\left(^{* *}\right) \mathrm{P}<0.01 ;\left({ }^{* * *}\right) \mathrm{P}<0.001$; ( $\left.{ }^{\text {n.s. }}\right)$ not significant; $\mathrm{n}=138 ; \rho_{\mathrm{d}}$ - bulk density dry; $\mathrm{P}_{\mathrm{T}}-$ total porosity; $\mathrm{P}_{\mathrm{N}}$ - coarse pores; $\mathrm{P}_{\mathrm{C}}-$ capillary pores; $\theta_{\mathrm{CMC}}-$ maximum capillary water capacity; $\theta_{\mathrm{V}}-$ wilting point; $\theta_{\mathrm{P}}-$ available water capacity; $\mathrm{V}_{\mathrm{A}}$ - air-filled porosity

participated in the increase of $\rho_{\mathrm{d}}$. Such correlation was in contrast with findings of Lal and Shukla [2004]. On the other hand, Safadoust et al. [2014] stated that increases in the percentage of clay might raise $\rho_{d}$ due to the filling of the space between the silt and sand particles. In the studied profiles, a well-known relationship that elevated clay content increases the percentage of $\mathrm{P}_{\mathrm{C}}$ and $\theta_{\mathrm{CMC}}$ was also confirmed highly significantly (Table 2). That was explained by Safadoust et al. [2014] as the larger amount of surface area that is available to retain moisture at high suctions. Ghanbrian-Alavijeh and Millán [2009] stated that appropriate combinations of fine soil particles (clay and silt) and organic materials could result in a highly complex (fractal) pore-solid interface, which raises the number of accessible sites for water molecules and improves the water retention at permanent wilting point. Similarly in this study, highly positive correlation between clay content and $\theta_{\mathrm{V}}$ (Table 2) confirmed the fact that in soil enriched by clay the water was bound stronger, and its considerable amount was physiologically dead, unavailable to plants. Ghanbrian-Alavijeh and Millán [2009] stated that a positive correlation between surface fractal dimension values and water content at permanent wilting point and clay content could indicate an increase of surface irregularity (geometrical complexity) due to chaotic orientation of clay pellets.

Kutílek [1978] stated that the soil particles with the size less than $0.01 \mathrm{~mm}$, similarly to clay, decrease the speed of water movement in soil, increase capillary lift of water, have proven adsorption ability, ion exchange and water retention. Moreover, in this study, the particles $<0.01 \mathrm{~mm}$ showed the same trend of correlations with the studied physical parameters as the clay. In the past, the percentage of particles $<0.01 \mathrm{~mm}$ was used for evaluating the textural classes in the former Czechoslovakia.

\section{Relationships between textural and physical parameters in individual horizons}

Considering merely topsoils, i.e. anthric (ak) and umbric (um) horizons, the correlations between sand and physical parameters had the same trends, which were even more pronounced, than the ones in entire soil profiles (Table 3). In topsoils, sand significantly contributed to rapid drainage of water into lower soil layers, as evidenced by highly positive correlation with $\mathrm{P}_{\mathrm{T}}, \mathrm{P}_{\mathrm{N}}$, and $\mathrm{V}_{\mathrm{A}}$ and negative with $\mathrm{P}_{\mathrm{C}}, \theta_{\mathrm{CMC}}$ and $\theta_{\mathrm{P}}$, and thereby significantly ensured sufficient aeration of topsoils.

The silt had very particular influence on the studied physical properties in topsoils (Table 3). Significantly negative correlation with $\mathrm{P}_{\mathrm{N}}, \mathrm{V}_{\mathrm{A}}$, highly positive with $\mathrm{P}_{\mathrm{C}}, \theta_{\mathrm{CMC}}$ and $\theta_{\mathrm{P}}$ suggests that in topsoils, the silt fraction functioned similarly to clay. Moreover, Lal and Shukla [2004] and Fulajtár [2006] mentioned that silt has moderate surface area, and therefore moderate water holding capacity, and also low ion exchange capacity.

The clay fraction in anthric and umbric horizons confirmed its strong bounding with water by highly positive correlation with $\theta_{\mathrm{v}}$ and negative with $\theta_{\mathrm{p}}$. Although the clay significantly influenced the increase of $\rho_{\mathrm{d}}$ and decrease of $\mathrm{P}_{\mathrm{T}}$, it did not influence volumes of $\mathrm{P}_{\mathrm{N}}$ and $\mathrm{P}_{\mathrm{C}}$ and therefore water retention in topsoils, as is evident from statistical evaluation. The correlations with other examined physical parameters and clay were insignificant (Table 3). This confirmed that in topsoils the usual function of clay was substituted by silt.

Fraction $<0.01 \mathrm{~mm}$ had the same trend as clay and moreover, obvious contribution of part of medium and fine silt $(0.01-0.002 \mathrm{~mm})$ to increase the correlation coefficients of $\rho_{\mathrm{d}}, \mathrm{P}_{\mathrm{T}}, \mathrm{P}_{\mathrm{N}}$, and $\mathrm{V}_{\mathrm{A}}$ was observed (Table 3 ).

Table 4 shows the correlations between textural fractions and the examined physical parameters found in compacted illuvial horizons 
(enriched by accumulated clay lessived from upper horizons) represented by luvic and stagnic horizons. Generally, the sand fraction contributes to increase the $\rho_{\mathrm{d}}$ and reduction $\mathrm{P}_{\mathrm{T}}$ [Fulajtár 2006], which was confirmed mainly in heavytextured soils (clay 54.4-76.6\%) [Obalum et al. 2011]. Moreover, in the examined illuvial horizons, this relationship was highly significant. In addition, sand significantly negatively correlated with $\mathrm{P}_{\mathrm{N}}$, which resulted in decreased aeration of $1 \mathrm{v}$ and st horizons $\left(\mathrm{V}_{\mathrm{A}}\right)$.

The relationship of silt with evaluated physical properties was very interesting. In illuvial horizons, the silt highly significantly contributed to the reduction of $\theta \mathrm{v}$ and $\rho_{\mathrm{d}}$ (Table 4). Highly positive correlation with the $\mathrm{P}_{\mathrm{T}}$, especially $\mathrm{P}_{\mathrm{N}}$ proves the fact that in the horizons enriched by clay, the silt fraction was involved in the formation of $\mathrm{P}_{\mathrm{T}}$, mainly $\mathrm{P}_{\mathrm{N}}$, thereby contributing to reduction of $\rho_{\mathrm{d}}$. This was confirmed by highly positive correlation with $\mathrm{V}_{\mathrm{A}}$, thus silt helped to increase ventilation and air exchange in compacted illuvial horizons. From the information above it can be concluded that in compacted illuvial horizons the silt was the most important fraction for $\mathrm{P}_{\mathrm{N}}$ formation. Conversely, in loose topsoils it was just the silt which significantly contributed to the reduction of coarse porosity as well as increased the volume of fine, capillary pores and so water retention.

Clay participated in highly significant reduction of $\mathrm{P}_{T}$, especially $\mathrm{P}_{\mathrm{N}}$, as well as significant diminution of aeration. The reduction of pores diameter due to increased clay content was also confirmed by Zangiabadi et al. [2017]. In this study, clay also significantly affected the formation of $\mathrm{P}_{\mathrm{C}}$ and $\theta_{\text {CMC }}$. Highly negative correlation between clay and $\theta_{\mathrm{V}}$ suggest that a considerable amount of water retained in illuvial horizons was physiologically unavailable for plants. Moreover, in illuvial horizons, the same trend as clay had the fraction $<0.01 \mathrm{~mm}$.

Considering merely eluvial, i.e. albic (ab) and fragic (fg), that is clay depleted horizons, the known relationships between the sand fraction and physical properties were clearly highlighted (Table 5). Sand contributed to a significant increase $\rho_{\mathrm{d}}$ and reduction of $\mathrm{P}_{\mathrm{T}}$ as well as $\mathrm{P}_{\mathrm{C}}, \theta_{\mathrm{CMC}}$, and despite the significant reduction of wilting point, it also participated in the declining of $\theta_{\mathrm{p}}$, which is consistent with the known facts reported in literature [Fulajtár 2006, Asgarzadeh et al. 2011].

In eluvial horizons, silt and clay fractions had similar relations with physical properties. Silt/clay negatively correlated with $\rho_{\mathrm{d}}$, positively with $\mathrm{P}_{\mathrm{T}}$ and of course capillary porosity, which can retain water and so mitigate its quick drainage, which is appropriate, since the examined $\mathrm{ab}$ and fg horizons contained up to $44.4-64.7 \%$ of sand (Fig. 3) and the volume of coarse porosity was $10.7-20.2 \%$ [Polláková et al. 2017]. Similarly, Zangiabadi et al. [2017] stated that in light textured soils, the positive impact of clay content on least limiting water range could be attributed to the effects of clay particles reducing the mean diameter of the soil pores and increment of soil water retention. In eluvial

Table 3. Pearson correlation coefficients (r) between particle-size distribution and physical parameters in topsoils (anthric and umbric) horizons

\begin{tabular}{|c|c|c|c|c|c|c|c|c|}
\hline particle size & $\rho_{d}$ & $P_{T}$ & $P_{N}$ & $P_{C}$ & $\Theta_{\mathrm{CMC}}$ & $\Theta \mathrm{v}$ & $\Theta p$ & $V_{A}$ \\
\hline $\mathrm{mm}$ & $\mathrm{t} \mathrm{m}^{-3}$ & \multicolumn{7}{|c|}{$\%$} \\
\hline $2-0.05$ & $-0.484^{* *}$ & $0.492^{* *}$ & $0.733^{* * *}$ & $-0.720^{* * *}$ & $-0.714^{* * *}$ & $-0.533^{* * *}$ & $-0.370^{*}$ & $0.731^{* * *}$ \\
\hline $0.05-0.002$ & $0.222^{\text {n.s. }}$ & $-0.240^{\text {n.s. }}$ & $-0.551^{* * *}$ & $0.677^{* * *}$ & $0.692^{* * *}$ & $0.022^{\text {n.s. }}$ & $0.647^{* * *}$ & $-0.562^{* * *}$ \\
\hline$<0.002$ & $0.378^{*}$ & $-0.365^{*}$ & $-0.271^{\text {n.s. }}$ & $0.077^{\text {n.s. }}$ & $0.046^{\text {n.s. }}$ & $0.730^{* * *}$ & $-0.380^{*}$ & $-0.254^{\text {n.s. }}$ \\
\hline$<0.01$ & $0.525^{\star * *}$ & $-0.519^{\star \star *}$ & $-0.502^{* *}$ & $0.309^{\text {n.s. }}$ & $0.285^{\text {n.s. }}$ & $0.772^{* * *}$ & $-0.179^{\text {n.s. }}$ & $-0.492^{* *}$ \\
\hline $0.01-0.002$ & $0.352^{*}$ & $-0.368^{*}$ & $-0.544^{* * *}$ & $0.541^{* * *}$ & $0.556^{* * *}$ & 0.122 & $0.452^{* *}$ & $-0.560^{* * *}$ \\
\hline
\end{tabular}

For abbreviations see Table $2 ; \mathrm{n}=39$

Table 4. Pearson correlation coefficients (r) between particle-size distribution and physical parameters in illuvial (luvic and stagnic) horizons

\begin{tabular}{|c|c|c|c|c|c|c|c|c|}
\hline particle size & $\rho_{d}$ & $\mathrm{P}_{\mathrm{T}}$ & $P_{N}$ & $P_{C}$ & $\Theta_{\mathrm{CMC}}$ & $\Theta v$ & $\Theta p$ & $\mathrm{~V}_{\mathrm{A}}$ \\
\hline $\mathrm{mm}$ & $\mathrm{t} \mathrm{m}^{-3}$ & \multicolumn{7}{|c|}{$\%$} \\
\hline $2-0.05$ & $0.606^{* * *}$ & $-0.616^{\star * *}$ & $-0.306^{*}$ & $-0.115^{\text {n.s. }}$ & $-0.263^{\text {n.s. }}$ & $0.112^{\text {n.s. }}$ & $0.162^{\text {n.s. }}$ & $-0.312^{*}$ \\
\hline $0.05-0.002$ & $-0.739^{* * *}$ & $0.772^{* * *}$ & $0.535^{* * *}$ & $-0.194^{\text {n.s. }}$ & $0.041^{\text {n.s. }}$ & $-0.448^{* * *}$ & $-0.078^{\text {n.s. }}$ & $0.560^{* * *}$ \\
\hline$<0.002$ & $0.362^{* *}$ & $-0.406^{* *}$ & $-0.472^{* * *}$ & $0.526^{\star * *}$ & $0.338^{*}$ & $0.621^{* * *}$ & $-0.115^{\text {n.s. }}$ & $-0.506^{* * *}$ \\
\hline$<0.01$ & $0.219^{\text {n.s. }}$ & $-0.245^{\text {n.s. }}$ & $-0.453^{* * *}$ & $0.654^{* * *}$ & $0.504^{* * *}$ & $0.484^{* * *}$ & $-0.312^{*}$ & $-0.481^{* * *}$ \\
\hline
\end{tabular}

For abbreviations see Table 2; $\mathrm{n}=54$ 
Table 5. Pearson correlation coefficients (r) between particle-size distribution and physical parameters in eluvial (albic and fragic) horizons

\begin{tabular}{|c|c|c|c|c|c|c|c|c|}
\hline particle size & $\rho_{d}$ & $\mathrm{P}_{\mathrm{T}}$ & $P_{N}$ & $\mathrm{P}_{\mathrm{C}}$ & $\Theta_{C M C}$ & $\Theta \mathrm{v}$ & $\Theta p$ & $V_{A}$ \\
\hline $\mathrm{mm}$ & $\mathrm{t} \mathrm{m}^{-3}$ & \multicolumn{7}{|c|}{$\%$} \\
\hline $2-0.05$ & $0.878^{* * *}$ & $-0.860^{* * *}$ & $0.108^{\text {n.s. }}$ & $-0.644^{* * *}$ & $-0.725^{\star * \star}$ & $-0.565^{\star *}$ & $-0.524^{* *}$ & $0.082^{\text {n.s. }}$ \\
\hline $0.05-0.002$ & $-0.504^{* *}$ & $0.492^{* *}$ & $-0.004^{\text {n.s. }}$ & $0.362^{*}$ & $0.366^{*}$ & $0.021^{\text {n.s. }}$ & $0.543^{* *}$ & $0.041^{\text {n.s. }}$ \\
\hline$<0.002$ & $-0.765^{\star * *}$ & $0.751^{* \star *}$ & $-0.138^{\text {n.s. }}$ & $0.567^{\star \star}$ & $0.669^{* * *}$ & $0.721^{* \star *}$ & $0.274^{\text {n.s. }}$ & $-0.137^{\text {n.s. }}$ \\
\hline$<0.01$ & $0.096^{\text {n.s. }}$ & $-0.085^{\text {n.s. }}$ & $0.079^{\text {n.s. }}$ & $-0.156^{\text {n.s. }}$ & $-0.090^{\text {n.s. }}$ & $0.234^{\text {n.s. }}$ & $-0.438^{*}$ & $0.041^{\text {n.s. }}$ \\
\hline
\end{tabular}

For abbreviations see Table $2 ; \mathrm{n}=30$

horizons, clay also highly significantly contributed to increase the values of wilting point (Table 5). However, silt fraction was significantly positively associated with the increase of water availability, which is essential in terms of meeting the plants needs, mainly in warm and dry climate.

Curiously, only in eluvial i.e. clay depleted horizons, the correlations of fraction $<0.01 \mathrm{~mm}$ with the soil physical properties were insignificant and did not follow the trend of clay (Tables 2-5).

\section{CONCLUSIONS}

Favorable combination of hydrophysical and textural soil properties probably helped in adaptation to the soil-environment conditions in Arboretum Mlyňany, also to the water-demanding exotic trees such as Chamaecyparis lawsoniana, Liriodendron tulipifera and Thuja plicata.

Evaluation of entire profiles had confirmed standard, expected relationships between the individual grain fractions and soil physical properties. However, differences have occurred when the correlations between texture and physical properties in individual horizons were evaluated.

Considering entire soil profiles, increased sand content significantly supported drainage of rainwater and soil aeration; silt contributed to decrease of soil bulk density and wilting point, increase total porosity and aeration as well as available water capacity; clay contributed to decrease in available water capacity, total, mainly coarse porosity, hence decrease of soil aeration, and rise in percentage of capillary pores and so water retention, as well as rise in values of wilting point.

In the studied profiles, great importance in improvement of unfavourable soil physical properties has been attributed to the silt. Considering merely compacted illuvial horizons, the silt was highly significantly involved in the formation of total, mainly coarse porosity, thereby increaseing soil aeration as well as reducing bulk density and wilting point. Conversely, in loose topsoils, silt significantly contributed to the reduction of coarse pores as well as increase of capillary pores and water retention, so it functioned as clay, since clay was partially depleted from topsoils by lessivage. In loose eluvial horizons, silt together with clay caused a significant increase total and mainly capillary porosity, which can retain water. Unlike clay, the silt increased the soil water availability, which is essential in terms of meeting the plant needs.

\section{Acknowledgements}

This work was supported by the Cultural and Educational Grant Agency of the Slovak Republic under Grant KEGA 013SPU-4/2019, and by the Integrated Infrastructure Operational Programme funded by the ERDF - the project no. ITMS2014+ 313011W580: "Scientific support of climate change adaptation in agriculture and mitigation of soil degradation".

\section{REFERENCES}

1. Asgarzadeh H., Mosaddeghi M.R., Mahboubi A.A., Nosrati A., Dexter A.R. 2011. Integral energy of conventional available water, least limiting water range and integral water capacity for better characterization of water availability and soil physical quality. Geoderma, 166, 34-42.

2. Cifra J. 1958. Short characteristic of soil conditions in the Arboretum Mlyňany. In: Benčat', F. (Ed.), Natural conditions of Arboretum Mlyňany, Slovak Academy of Science, Bratislava, 79-96, (in Slovak).

3. Čimo J., Šinka K., Novotná B., Tárník A., Aydin E., Toková L., Kišš V., Kotuš T. 2020. Change in Temperature Conditions of Slovakia to the Reference Period 1961-2010 and their Expected Changes to Time Horizons Years 2035, 2050, 2075 and 2100 under the Conditions of Changing Climate. Journal of Ecological Engineering, 21(7), 232-240.

4. European Environment Agency. 2017. Climate change, impacts and vulnerability in Europe 2016, An indicator-based report. Publications Office of the 
European Union, Luxembourg.

5. Ferus P., Hot'ka, P., Košútová, D., Konôpková, J. 2020. Invasions of alien woody plant taxa across a cluster of villages neighbouring the Mlynany Arboretum (SW Slovakia). Folia Oecologica, 47(2), 121-130.

6. Fulajtár E. 2006. Physical properties of soil. Soil Science and Conservation Research Institute, Bratislava, (in Slovak).

7. Gera M., Damborská I., Lapin M., Melo, M. 2019. Climate changes in Slovakia: Analysis of past and present observations and scenarios of future developments. In: Barceló D., Kostianoy A.D. (Ed.). The handbook of environmental chemistry. Springer Nature Switzerland, Cham, 21-51.

8. Ghanbarian-Alavijeh B., Millán, H. 2009. The relationship between surface fractal dimension and soil water content at permanent wilting point. Geoderma, 151, 224-232.

9. Heiskanen J., Saksa T., Hyvöne J. 2016. Effects of mounding and soil clay content on postplanting success of Norway spruce. Forest Ecology and Management, 378, 206-213.

10. Hosseini F., Mosaddeghi M.R., Hajabbasi M.A., Sabzalian M.R. 2016. Role of fungal endophyte of tall fescue (Epichloë coenophiala) on wateravailability, wilting point and integral energy in texturally-differentsoils. Agricultural Water Management, 163, 197-211.

11. Hot'ka P., Barta M. 2012. Inventory of living collections of the Mlynnany Arboretum SAS. Slovak Academy of Science, Bratislava, (in Slovak).

12. Hrubík P., Holečková D. 2016. Analysis of the essential climatic factors in the Arboretum Mlyňany SAS in Vieska nad Žitavou for the period 2001-2015. Proc. Slovak Academy of Science, 129-136, (in Slovak).

13. Hrubík P., Hot'ka P. 2007. The climatic conditions characteristics of Arboretum Mlyňany SAS during period 1971-2006 (2007). Proc. Slovak Academy of Science, 28-37 (in Slovak).

14. Huxley A.J., Griffiths M., Levy M., 1992. The new Royal Horticultural Society dictionary of gardening. Macmillan, London.

15. Ištoňa J., Pavlenda P. 2011. Monitoring of water storage in forest soils on PMP Čifáre in the years 1999-2009. Forestry Journal, 57, 178-186.

16. Kobza J., HrivňákováK., MakovníkováJ., Barančíková G., Bezák P., Bezáková Z., Dodok R., Grečo V., Chlpík J., Lištjak M., Mališ J., Píš V., Schlosserová J., Slávik O., Styk J., Širáň, M. 2011. Obligatory methods of soil analyses. Soil science and conservation research institute, Bratislava (in Slovak).

17. Kutílek M. 1978. Water management pedology. SNTL - state publishing of technical literature, Praha, (in Czech).

18. Lal R. 1979. Physical properties and moisture retention characteristics of some Nigerian Soils. Geoderma, 21, 209-223.
19. Lal R., Shukla M.K. 2004. Principles of soil physics. Marcel Dekker, New York.

20. Marković M., Filipović V., Legović T., Josipović M. \& Tadić V. 2015. Evaluation of different soil water potential by field capacity threshold in combination with a triggered irrigation module. Soil and Water Research, 10, 164-171.

21. Mezősi G., Blanka V., Ladányi Z., Bata T., Urdea P., Frank A., Meyer B.C. 2016. Expected mid- and long-term changes in drought hazard for the SouthEastern Carpathian basin. Carpathian Journal of Earth and Environmental Sciences, 11(2), 355-366.

22. Minasny B., McBratney A.B. 2003. Integral energy as a measure of soil-water availability. Plant and Soil, 249, 253-262.

23. Ministry of Environment. 2017. Adaptation Strategy of the Slovak Republic on Adverse Impacts of Climate Change - update. Ministry of Environment of the Slovak Republic, Bratislava, (in Slovak).

24. Obalum S.E., Nwite J.C., Oppong J., Igwe C.A., Wakatsuki T. 2011. Variations in selected soil physical properties with landforms and slope within an inland valley ecosystem in Ashanti region of Ghana. Soil and Water Research, 6, 73-82.

25. De Paepe J.L., Bono A.A., Alvarez R. 2017. Simple estimation of available water capacity in soils of semiarid and subhumid environments. Arid Land Research and Management, 32(2), 133-148.

26. Poesen J.W., Lavee H. 1994. Rock fragments in top soils: Significance and processes. Catena, 23, 1-28.

27. Polláková N. 2018. Soils classified in the Arboretum Mlyňany, Slovakia. Folia Oecologica, 45(2), 120-128.

28. Polláková N., Šimanský V., Jonczak J. 2017. Characteristics of physical properties in soil profiles under selected introduced trees in the Nature Reserve Arboretum Mlyňany, Slovakia. Folia Oecologica, 44(2), 78-86.

29. Safadoust A., Feizee P., Mahboubi A.A., Gharabaghi B., Mosaddeghi M.R., Ahrens B. 2014. Least limiting water range as affected by soil texture and cropping system. Agricultural Water Management, 136, 34-41.

30. Statistica. 2008. Statistica. StatSoft, Praha.

31. Wall A., Heiskanen J. 2009. Soil-water content and air-filled porosity affect height growth of Scots pine in afforested arable land in Finland. Forest Ecology and Management, 257, 1751-1756.

32. Whitmore A.P., Whalley W.R. 2009. Physical effects of soil drying on roots and crop growth. Journal of Experimental Botany, 60, 2845-2857.

33. Zangiabadi M., Gorji M., Shorafa M., Khorasani S.K., Saadat, S. 2017. Effects of soil pore size distribution on plant available water and least limiting water range as soil physical quality indicators. Pedosphere, 30(2), 1-10. 